\title{
Simultaneous transurethral resection of the prostate and cystolithotripsy: A urological dilemma examined
}

Sander Mekke, $\mathrm{MD}^{1}$; Hossain Roshani, MD, $\mathrm{PhD}^{1}$; Paul van Zanten, $\mathrm{MD}^{2}$; Lorena Grondhuis Palacios, $\mathrm{MD}^{3}$; Joost Egberts, $\mathrm{MD}^{4}$; Nora Hendriks, MD ${ }^{5}$; Mischa Wijffelman, $\mathrm{MD}^{5}$; Willemijn Zonneveld, $\mathrm{MD}^{4}$; Bob Merks, $\mathrm{MD}^{3}$; Sarah van Loopik, $\mathrm{MD}^{2}$; Tim Buddingh, MD, $\mathrm{PhD}^{1}$

${ }^{1}$ Department of Urology, Haga Teaching Hospital, The Hague, The Netherlands; ${ }^{2}$ Department of Urology, Reinier de Graaf Gasthuis, Delft, The Netherlands; ${ }^{3}$ Department of Urology, Haaglanden Medisch Centrum, Den Haag, The Netherlands; ${ }^{4}$ Department of Urology, Leiden University Medical Center, University of Leiden, Leiden, The Netherlands; ${ }^{5}$ Department of Urology, Alrijne Health Care Group, Leiden/Leiderdorp, The Netherlands

Acknowledgment: The authors would like to thank Prof. Dr F.R. Rosendaal for his professional guidance in statistics.

Cite as: Mekke S, Roshani S, van Zanten P, et al. TURP simultaneously with cystolithotripsy? A urological dilemma examined. Can Urol Assoc J 2020 December 15; Epub ahead of print. http://dx.doi.org/10.5489/cuaj.6743

Published online December 15, 2020

$* * *$

\section{Abstract}

Introduction: Controversy exists over whether transurethral resection of the prostate (TURP) in men with bladder stones prevents recurrence of stone formation and facilitates stone discharge. We sought to evaluate whether TURP in patients who underwent cystolithotripsy led to a lower recurrence of bladder stones for which a re-cystolithotripsy was necessary. Methods: Patients $(n=127)$ who underwent transurethral cystolithotripsy with $(n=38)$ or without simultaneous TURP $(n=89)$ between January 2009 and December 2013 were retrospectively included in five centers in the Netherlands. Median followup was 48 months. The primary endpoint was to compare the relative risk between both groups for recystolithotripsy due to recurrent bladder stones. Secondary outcomes were the relative risk of urinary retention, the need for a (re-)TURP and the average time until recurrence.

Results: Patients who underwent a cystolithotripsy with a simultaneous TURP had a lower need for re-cystolithotripsy, resulting in a risk reduction of $72 \%$. (relative risk [RR] 0.28 [0.07$1.13], \mathrm{p}=0.06$, number needed to treat $[\mathrm{NNT}]=7$ ). The length of in hospital stay (3.4 vs. 1.6 days, $\mathrm{p}<0.01)$ and operative time ( 58 vs. 33 minutes, $\mathrm{p}<0.01$ ) was longer when a TURP was performed. There was no significant difference in complication rate, occurrence of urinary retention, re-TURP, and re-admission. Eighty-one percent of patients who did not undergo a 
TURP remained free of bladder stone recurrence. Due the retrospective nature of the study, essential data concerning prostate volume and micturition analysis was lacking.

Conclusions: A simultaneous TURP in patients who underwent a cystolithotripsy showed a trend towards a protective effect on the need for re-cystolithotripsy.

\section{Introduction}

In Western countries, five percent of all stones that occur in the urinary tract are bladder stones (1). The formation of bladder stones occurs mainly in patients with bladder outlet obstruction (BOO), neurogenic bladder dysfunction, chronic bacteriuria, foreign bodies such as an indwelling catheter, bladder diverticula, bladder augmentation, urinary deviations and in patients with stone formation in the upper urinary tract. The cause of bladder stone formation in $88 \%$ of adults is due to a form of BOO, in particular benign prostatic hyperplasia (BPH) (2). A bladder stone as an additional finding occurs in two percent of patients undergoing prostate resection due to BPH (3). The recurrence rates of bladder stones after cystolithotripsy is small (0-17\%) (610). However, the urological dilemma remains whether there is an indication for transurethral resection of the prostate (TURP) in men with a bladder stone to prevent recurrence of bladder stone formation and facilitate stone discharge $(2,4,5)$. Therefore, we evaluated whether a simultaneous TURP in patients who underwent cystolithotripsy led to a lower recurrence of bladder stones for which a re-cystolithotripsy was needed.

\section{Methods}

\section{Outcomes}

The primary outcome was the relative risk for a re-cystolithotripsy due to recurrent bladder stones in patients treated previously with cystolithotripsy without initial TURP compared to patients who underwent a TURP simultaneously. Secondary outcomes were the relative risk of urinary retention ( $>30$ days after the procedure) and the need for a (re-)TURP.

Furthermore, the average time till recurrence was analyzed.

\section{Patient selection and data collection}

In this retrospective multicenter study, patients were identified by Common Procedural Technology (CPT) codes in the Haga Teaching Hospital (The Hague), Reinier de Graaf Gasthuis (Delft), Haaglanden Medisch Centrum (The Hague), Leiden University Medical Center at the University of Leiden (Leiden) and Alrijne Health Care Group (Leiden). All patients who underwent a transurethral cystolithotripsy with or without TURP between January 2009 and December 2013 were included. Exclusion criteria were a neurogenic bladder, a form of BOO other than BPH (e.g. urethral stricture), a previous TURP, an earlier cystolithotripsy or an indwelling catheter.

Patient characteristics, stone characteristics (number and size), perioperative data (cystolithotripsy technique, volume of resected prostate tissue, operating time, the length of in 
hospital stay, complications and readmissions), postoperative medication use and follow-up data (urinary retention, (re-)TURP, and re-cystolithotripsy) were collected.

The bladder stone(s) were diagnosed either by flexible cystoscopy or by kidney, ureter, bladder (KUB) X-ray. The last follow-up date was defined as the last visit to the urological outpatient clinic or as the last visit to another specialist if a full medical history was noted during that visit. Complications were defined according to the Clavien-Dindo classification from treatment up to 30 days after dismissal.

All patients underwent a transurethral form of stone disintegration. The stone was either removed through the shaft, fragmented by mechanical cystolithotripsy or by laser cystolithotripsy. Indications for the applied techniques could not be found and was likely dependent on the stone size, operator experience and available techniques in the operating theater. Treatment with an alpha blocker, 5-alpha reductase inhibitor (5-ARI) or a combination of both were administered in case of persisting lower urinary tract symptoms (LUTS).

The study was conducted according to the principles of the Declaration of Helsinki (Ethics manual World Association 2nd edition 2009) and in accordance with the Dutch Medical Research Involving Human Subjects Act (WMO). The study was approved by the Medical Ethics Committee of South West Holland (19-027).

\section{Data analysis and interpretation}

Statistical analysis was conducted with IBM SPSS Statistics version 25. The analysis for categorical variables was performed with the Chi-square test and Fisher's exact test. For the analysis of normally distributed, continuous variables the unpaired t-test was used. Time to recurrence was displayed with a Kaplan-Meier curve and the difference was tested with the log-rank test. Univariate and multivariate logistic regression analysis were performed to identify variables that could be associated with a re-cystolithotrypsy. P-values $<0.05$ were considered statistically significant.

\section{Results}

A total of 127 patients were included. The patients were disproportionately distributed among the centers; the most contributing center included 49 (39\%) patients and the least only one $(0.8 \%)$ patient. In the other centers, $35(27.5 \%), 30(23.6 \%)$ and $11(8.7 \%)$ patients were included. Of the 127 patients, 38 (29.9\%) patients received a TURP simultaneously with cystolithotripsy. The median follow-up duration was 48 (0-111) months. Patient characteristics are shown in Table 1. Average age of patients who underwent a cystolithotripsy without TURP was significantly lower than the age of patients who underwent a cystolithotripsy combined with TURP ( 70 vs. 74 years).

The number of re-cystolithotripsy in the group with TURP was $2(5 \%)$ compared to 17 $(19 \%)$ in the group without TURP, resulting in a risk reduction of $72 \%$ (RR $0.28,95 \%$ CI $0.07-1.13, p=0.06$ ). Based on a causal link and similar patient groups, this corresponds to a number needed to treat (NNT) of 7. 
When the patiënts who received medical treatment for BPH (alpha blockers, 5-ARI or combination therapy) postoperative after cystolithotripsy are included in the intervention group, the NNT is 6 (RR $0.35,95 \%$ CI $0.14-0.90, p=0.03$ )

In the univariate and multivariate logistic regression analysis, only simultaneous TURP showed a trend toward significant association with re-cystolithotripsy (Table. 2).

Perioperatively, stone forceps and laser were more often used when TURP was not performed. Patients treated by stone forceps or laser were all suffering from a single bladder stone and were more frequently treated with an alfa blocker or 5-ARI postoperatively.

The length of in hospital stay (3.4 vs. 1.6 days; $p<0.01$ ) and operating time (58 vs. 33 minutes; $p<0.01$ ) in the group with TURP was significantly longer than in the group without a TURP (Table. 3). No significant differences were seen in the number of complications and readmissions.

The long-term outcomes of both groups are shown in Table. 4. There were no significant differences in the occurrence of urinary retention ( $3 \%$ with TURP vs. $10 \%$ without) or number of (re-)TURPs (16\% vs. $18 \%)$.

The stone recurrence-free period between the two groups differed in favor of the group with TURP (fig. 1, log-rank key $p=0.09$ ). In the early years there was no difference between the groups, but from 30 months postoperatively the curves began to vary clearly.

\section{Discussion}

We investigated whether a simultaneous TURP in patients who underwent cystolithotripsy led to a lower recurrence of bladder stones for which a re-cystolithotripsy would be needed. In this multicenter study, performance of a TURP at the time of cystolithotripsy showed a trend toward a protective effect against re-cystolithotripsy. In the group of patients who did undergo a TURP, 95\% remained free of bladder stone relapse in 48 months postoperative, compared to $81 \%$ the patients who did not undergo a TURP. Patients who received both a cystolithotripsy and TURP simultaneously had a significant longer operating time and the length of in hospital stay, while no significant differences were found in complication rate, percentage of urinary retentions and number of (re-)TURPs.

Only very limited patient series have been reported on the protective effect of TURP on the recurrence of bladder stones. Prodromos Phillopou et al. is the only prospective nonrandomized study that compared cystolithotripsy with TURP to cystolithotripsy with medical treatment of BPH (10). A total of 64 patients participated in their study. In both groups, the International Prostate Symptoms Score (IPSS) and peak urinary flow rate $\left(\mathrm{Q}_{\max }\right)$ improved significantly after treatment. In $34 \%$ of patients, conservative therapy of BPH failed and these patients still underwent a TURP. In both groups, only one patient had a recurrent bladder stone. The limited follow-up duration in this study was only 28 months. This may explain the lower number of recurrences.

The recurrence rate of bladder stones in our study is 19\% during 48 months follow-up in the group without TURP. This is comparable to the study performed by Yoshida et al. (7). In their retrospective study, 34 men were included with a bladder stone for which they 
underwent transurethral cystolithotripsy and received conservative treatment for BPH. The average follow-up duration was 53 months. Eighteen percent of the patients had bladder stone recurrence for which surgical intervention was necessary.

Other retrospective studies showed a varying recurrence rate of $0-17 \%$ during a follow-up duration of 10 to 30 months. Studies with the shortest follow-up reported the lowest recurrence rates (6-9). The number of patients who underwent a TURP afterwards in our present study (18\%) is comparable with what is reported in the literature, which is $12-34 \%$ $(8,10)$.

Our study showed a longer operating time and the length of in hospital stay in the group who underwent a TURP simultaneously with cystolithotripsy. Nevertheless, the complication rate was not higher in this group. Known complications that may occur in the short term after a TURP are acute urinary retention (4.5\%), clot retention (4.9\%) and urinary tract infection (4.1\%) (11). Long term complications are retrograde ejaculation $(65.4 \%)$, bladder neck sclerosis $(4.7 \%)$, urethral stricture $(3.8 \%)$ and persistent urgency $(2.2 \%)(11,12)$.

In our opinion, the short- and long-term complications of a TURP should be considered when counseling the patient to perform a TURP simultaneously with a cystolithotripsy.

Significant preoperative LUTS or a large postvoid residual urine volume may lead to perform TURP simultaneously with cystolithotripsy. However, these parameters are out of this manuscript's focus and are not reported. O'Conner et al. examined this effect in detail (8). In their prospective study, medical treatment of BPH combined with surgical treatment of a bladder stone led to a substantial reduction in IPSS (18 vs. 9) and postvoid residual urine volume ( $350 \mathrm{vs} .170 \mathrm{cc}$ ). They conclude that a cystolithotripsy without TURP, in combination with medical therapy, might result in a significant reduction of LUTS.

A relevant limitation of our study is its retrospective nature. As a result, there was insufficient data on preoperative prostate volume, and the pre- and postoperative micturition analysis of patients. Therefore, it cannot be ruled out that the NNT of 7 would be different to this study if a randomized trial had been carried out with complete data. The strength of the present study is the number of patients included and the long follow-up time, which were respectively higher and often longer compared to previous studies described in literature.

\section{Conclusions}

In this multicenter retrospective cohort study, a simultaneous TURP in patients who underwent a cystolithotripsy showed a trend towards a protective effect on the need for recystolithotripsy. Of the patients who did not undergo a TURP, $81 \%$ had no recurrence of a bladder stone at 48 months follow-up. Shared decision making is the key to decide whether to perform an TURP simultaneously in patients undergoing cystolithotripsy. 


\section{References}

1. Schwartz BF, Stoller ML. The vesical calculus. Urol Clin North Am 2000;27:333-46.

2. Douenias R, Rich M, Badlani G et al. Predisposing factors in bladder calculi. Review of 100 cases. Urology 1991;37:240-3.

3. McConnell JD. Benign prostatic hyperplasia. J Urol 1994;152(2 Pt 1):459-60.

4. Mebust WK, Holtgrewe HL, Cockett AT et al. Transurethral prostatectomy: immediate and postoperative complications. Cooperative study of 13 participating institutions evaluating 3,885 patients. J Urol 2002;167:5-9.

5. Oelke M, Bachmann A, Descazeaud A et al. EAU guidelines on the treatment and follow-up of non-neurogenic male lower urinary tract symptoms including benign prostatic obstruction. Eur Urol 2013;64:118-40.

6. Millan-Rodriguez F, Izquierdo-Latorre F, Montlleo-Gonzalez M et al. Treatment of bladder stones without associated prostate surgery: results of a prospective study. Urology 2005;66:505-9.

7. Yoshida T, Kinoshita H, Nakamoto $\mathrm{T}$ et al. Conservative treatment for benign prostatic hyperplasia in patients with bladder stones. Urology 2015;86:450-3.

8. O'Connor RC, Laven BA, Bales GT et al. Nonsurgical management of benign prostatic hyperplasia in men with bladder calculi. Urology 2002;60:288-91.

9. Tzortzis V, Aravantinos E, Karatzas et al. Percutaneous suprapubic cystolithotripsy under local anesthesia. Urology 2006;68:38-41.

10. Philippou P, Volanis D, Kariotis I et al. Prospective comparative study of endoscopic management of bladder lithiasis: is prostate surgery a necessary adjunct? Urology. 2011;78:43-7.

11. Ahyai SA, Gilling P, Kaplan SA et al. Meta-analysis of functional outcomes and complications following transurethral procedures for lower urinary tract symptoms resulting from benign prostatic enlargement. Eur Urol 2010;58: 384-97.

12. Madersbacher S, Marberger M. Is transurethral resection of the prostate still justified? BJU Int. 1999 Feb;83:227-37. 


\section{Figures and Tables}

Fig. 1. Stone recurrence-free period. TURP: transurethral resection of the prostate.

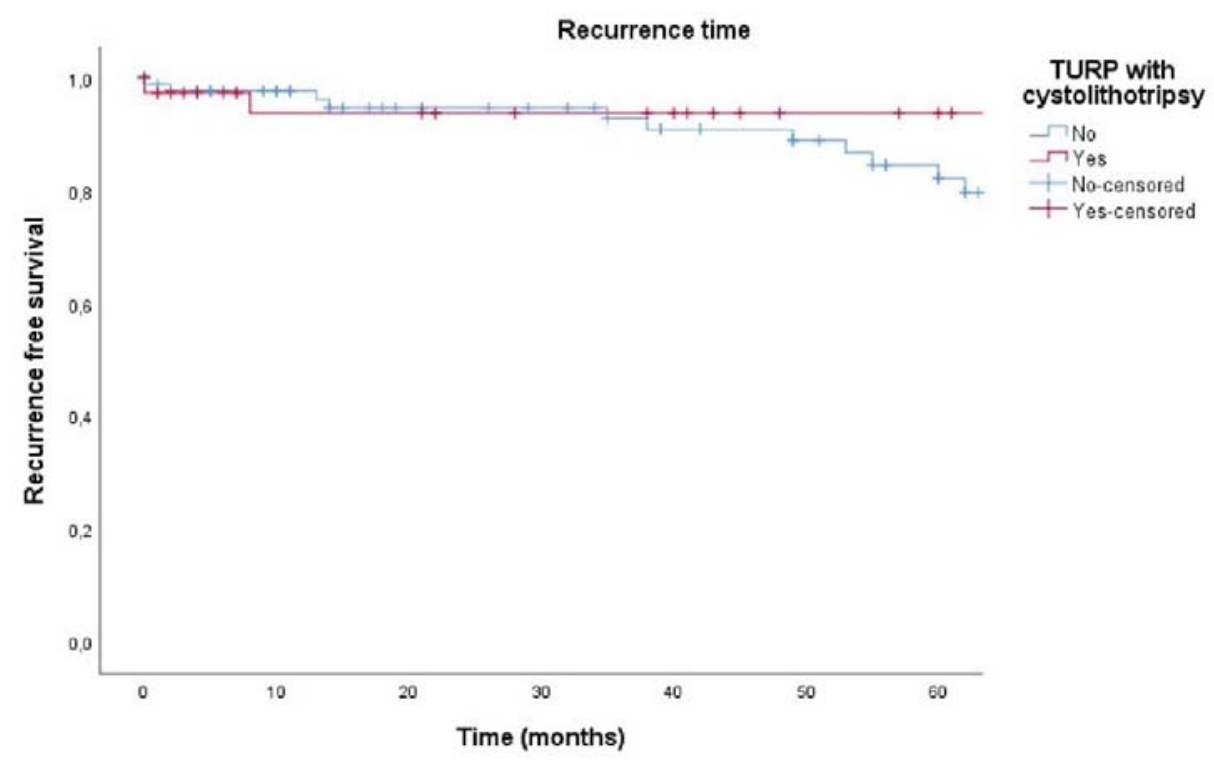

\begin{tabular}{|c|c|c|c|}
\hline & $\begin{array}{c}\text { Cystolithotripsy } \\
\text { with TURP } \\
(\mathrm{n}=\mathbf{3 8})\end{array}$ & $\begin{array}{c}\text { Cystolithotripsy } \\
\text { without TURP } \\
(n=89)\end{array}$ & $\mathbf{p}$ \\
\hline Age (years) & 74 & 70 & 0.04 \\
\hline \multicolumn{4}{|l|}{ Number of stones } \\
\hline 1 & $18(49 \%)$ & $60(67 \%)$ & 0.04 \\
\hline$\geq 2$ & $19(51 \%)$ & $29(33 \%)$ & 0.04 \\
\hline Max diameter $^{*}(\mathrm{~cm})$ & 1.7 & 1.8 & 0.99 \\
\hline \multicolumn{4}{|l|}{ Operation technique $^{* *}$} \\
\hline Through the shaft & $7(25 \%)$ & $6(10 \%)$ & 0.04 \\
\hline $\begin{array}{l}\text { Mechanical or laser } \\
\text { lithotripsy }\end{array}$ & $21(75 \%)$ & $56(90 \%)$ & 0.04 \\
\hline Volume TURP-tissue (g) & 17 & - & - \\
\hline \multicolumn{4}{|l|}{ Postoperative medication $^{* * *}$} \\
\hline Alpha blocker & $1(3 \%)$ & $25(28 \%)$ & 0.01 \\
\hline 5-ARI & $3(8 \%)$ & $12(13 \%)$ & 0.65 \\
\hline $\begin{array}{l}\text { Median followup } \\
\text { (months) }\end{array}$ & 44 & 49 & 0.79 \\
\hline
\end{tabular}

${ }^{*}$ Missing data 38\%. ${ }^{* *}$ Missing data 30\%. ${ }^{* * *}$ Missing data 31\%. 5-ARI: 5-alpha reductase inhibitor; TURP: transurethral resection of the prostate. 


\begin{tabular}{|c|c|c|c|c|c|c|c|c|}
\hline \multirow[t]{2}{*}{ Covariate } & \multirow[t]{2}{*}{ Patients } & \multirow{2}{*}{$\begin{array}{c}\mathrm{Re}- \\
\text { cystolithotripsy }\end{array}$} & \multicolumn{3}{|c|}{ Univariate } & \multicolumn{3}{|c|}{ Multivariate } \\
\hline & & & OR & $\begin{array}{c}\text { CI } \\
(95 \%)\end{array}$ & $\mathbf{p}$ & OR & $\begin{array}{c}\text { CI } \\
(95 \%)\end{array}$ & $\mathbf{p}$ \\
\hline $\begin{array}{l}\text { Simultaneous } \\
\text { TURP }\end{array}$ & & & 0.24 & $\begin{array}{l}0.05- \\
1.08\end{array}$ & 0.06 & 0.25 & $\begin{array}{l}0.05- \\
1.140\end{array}$ & 0.07 \\
\hline Yes & 28 & 2 & & & & & & \\
\hline No & 89 & 17 & & 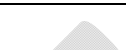 & & & & \\
\hline Age (years) & & & 0.53 & $\begin{array}{c}0.20- \\
1.41\end{array}$ & 0.20 & 0.58 & $\begin{array}{c}0.21- \\
1.57\end{array}$ & 0.28 \\
\hline$<70$ & 52 & 10 & & 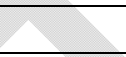 & & & & \\
\hline$\geq 70$ & 75 & 9 & 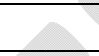 & 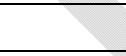 & & & & \\
\hline $\begin{array}{l}\text { Number of } \\
\text { stones }\end{array}$ & & & 1.57 & $\begin{array}{c}0.59- \\
4.19\end{array}$ & 0.37 & & & \\
\hline 1 & 78 & 10 & 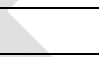 & & 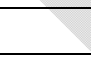 & & & \\
\hline$\geq 2$ & 48 & 9 & 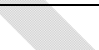 & 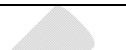 & & & & \\
\hline $\begin{array}{l}\text { Postoperative } \\
\text { medication } \\
\text { use }^{*}\end{array}$ & & & 0.72 & $\begin{array}{l}0.21- \\
2.54\end{array}$ & 0.61 & 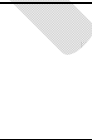 & & \\
\hline Yes & 30 & 4 & + & 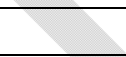 & & & & \\
\hline No & 57 & 10 & 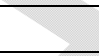 & 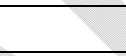 & & & & \\
\hline
\end{tabular}

*5-alpha reductase inhibitor and/or alpha blocker, missing data 31\%. 5-ARI: 5-alpha reductase inhibitor; CI: confidence interval; OR: odds ration; TURP: transurethral resection of the prostate. 


\begin{tabular}{|l|c|c|c|}
\hline \multicolumn{1}{|l|}{ Table 3. Perioperative outcomes } \\
\hline & $\begin{array}{c}\text { Cystolithotripsy } \\
\text { with TURP } \\
\text { (n=38) }\end{array}$ & $\begin{array}{c}\text { Cystolithotripsy } \\
\text { without TURP } \\
\text { (n=89) }\end{array}$ & p \\
\hline Operating time (min) & 58 & 33 & $<0.01$ \\
\hline $\begin{array}{l}\text { Length of in hospital } \\
\text { stay (days) }\end{array}$ & 3.4 & 1.6 & 0.04 \\
\hline Complications & $6(15.8 \%)$ & $20(22.5 \%)$ & 0.39 \\
\hline Grade I & $4(10.5 \%$ & $17(19.1 \%)$ & - \\
\hline Grade II & $1(2.6 \%)$ & $3(3.4 \%)$ & - \\
\hline Grade III & $1(2.6 \%)$ & 0 & - \\
\hline Readmissions & $3(9 \%)$ & $4(5 \%)$ & 0.45 \\
\hline
\end{tabular}

TURP: transurethral resection of the prostate.

\begin{tabular}{|l|c|c|c|c|}
\hline Table 4. Long term outcomes & $\begin{array}{c}\text { Cystolithotripsy } \\
\text { with TURP } \\
(\mathbf{n = 3 8 )}\end{array}$ & $\begin{array}{c}\text { Cystolithotripsy } \\
\text { without TURP } \\
(\mathbf{n = 8 9 )}\end{array}$ & RR (95\% CI) & p \\
\hline Re-cystolithotripsy & $2(5 \%)$ & $17(19 \%)$ & $0.28(0.07-1.13)$ & 0.06 \\
\hline $\begin{array}{l}\text { Urinary retention } \\
(>30 \text { days after the } \\
\text { procedure) }\end{array}$ & $3(8 \%)$ & $9(10 \%)$ & $0.72(0.88-1.15)$ & 1.0 \\
\hline $\begin{array}{l}\text { Median time till } \\
\text { urinary retention } \\
\text { (months) }\end{array}$ & 21.8 & 4.5 & - & 0.75 \\
\hline Re-TURP & $6(16 \%)$ & $16(18 \%)$ & $0.88(0.37-2.07)$ & 1.0 \\
\hline
\end{tabular}

CI: confidence interval; RR: relative risk; TURP: transurethral resection of the prostate. 